\title{
Doctor to Patient Ratio and Infrastructure Gap in a Psychiatric Hospital in Oil Rich Eket, Nigeria
}

\section{Uche Adolphus Nwaopara*}

Psychiatric Hospital Eket, Nigeria

\begin{abstract}
Background: In an oil rich city, profound shortfalls in the human resources and basic infrastructure, needed for adequate mental health care is dehumanizing and unacceptable.
\end{abstract}

Aims: To bring to global attention, the population-provider ratio, the wide mismatch between the doctors and infrastructure available to patients and the implications of such mental health gap.

Method: In this cross sectional retrospective study, 870 patients who presented to the center over a 3-month period (May-July) were reviewed. The Federal Ministry of Health, National Health management Information System, Health Facility Daily Attendance Register (Version 2013) was used to review the patients in terms of outpatient, inpatient, specialist medical care and outcome. The Hospital Inpatient Facilities Checklist (for Psychiatric Units), was used to access the level of facilities and compliance to standards at this center. Data analysis was done using SPSS Version 17

Results: In a 74-bed hospital, there were $6(8.1 \%)$ beds, leaving a shortfall of $68(91.9 \%)$ beds with bed to population ratio of $3: 100,000$ (critical bed shortage, <12 per 100,000), with many patients lying on the bare floor. The bed to population ratio was 3:100,000. The doctor/patient ratio was 1:870 (One Psychiatrist) or 1:435 (medical officer + psychiatrist) and a psychiatrist to population ratio of 0.48 per 100,000 . Psychiatric presentations were commoner among females $51.4 \%$. The most prevalent psychiatric disorder was Schizophrenia with 401 (46.09\%) patients. The prevalence of Mental and Behavioral disorder was 9.08 (9.1\%). Other factors were no toilet facilities, laundry services with huge public health implications.

Conclusions: Research findings show resource gaps. This mismatch of disease burden with extant resources is evidence of failure in systemic health delivery and failure of corporate social responsibility. A reversal of this ugly trend will help to improve efficiency in service delivery as well as optimize patient care and reduce the treatment gap.

Keywords: Patient; Ratio; Gap; Infrastructure; Resource

\section{Introduction}

Mental health resources remain one of the most neglected areas in healthcare in sub-Saharan Africa [1]. Although mental ill health constitutes a huge portion of the Global Burden of Disease (GBD), the majority of people with mental health problems do not receive any treatment, a scenario, much worse in developing countries where mental health personnel are in gross short supply [2].

Ageing and crumbling infrastructure still pose a huge problem, owing to the gross neglect suffered by mental health hospitals over the years. Roofs with gaping holes, broken down toilet facilities, some horrible consulting rooms and wards in catastrophic conditions are a common place at this hospital [3].

The inadequacy in services has been reported not only in the form of quantity but also in the quality of mental health services with persisting human rights violations in mental health institutions [4]. A report by National Human Rights Commission mentions that many institutions still retained a prison-like structure and ambience. With patients locked in iron crested doors, put on big chains and tied to window protectors and prison-like practices such as roll-call and lining up for handover and feeding still existed [5]. Exclusively closed wards existed in 59\% of the hospitals examined [6]. The building maintenance was unsatisfactory in many hospitals with leaking roofs, eroded doors, overflowing toilets and broken doors. The overall ratio of beds to patients was 1:1.4, indicating that many patients slept on the floor. There are no functional toilets and patients urinates and defecates in the cell, and archaic practices like shaving heads (for both male and female patients) and chaining disruptive patients outside in unfavorable weather conditions were still prevalent at the time of study [6]. At the Psychiatric hospital, Eket, the situation is not different. There are no functional toilets and patients urinate and defecate in the cell with archaic practices like shaving heads (for both male and female patients) and chaining disruptive patients outside in unfavorable weather were still prevalent, at the time of study, with huge public health implications..

In Nigeria, public sector allocation to mental illness is small, with lip service being paid to the issue of improving the mental health care structures and service [7]. Less than 3\% of Gross Domestic Product (GDP) is spent on health and of this less than $1 \%$ is allocated to mental health institutions and services [7]. The figure recommended by the WHO for mental health is $5 \%$, and in many countries it is about $15 \%$ [8]. The very low level of expenditure on psychiatry in Nigeria, manifest in the decay of infrastructure, as is the case in this state owned psychiatric hospital located in an oil rich city. It also means that even

*Corresponding author: Uche Adolphus Nwaopara, Psychiatric Hospital Eket, No 19 Egbelu Street Rumuodara Port Harcourt, Rivers 234, Nigeria, Tel: +2348069008876; E-mail: mceeuche@yahoo.com

Received September 25, 2015; Accepted March 05, 2016; Published March 12 2016

Citation: Nwaopara UA (2016) Doctor to Patient Ratio and Infrastructure Gap in a Psychiatric Hospital in Oil Rich Eket, Nigeria. J Psychiatry 19: 356 doi:10.4172/2378-5756.1000356

Copyright: ( 2016 Nwaopara UA. This is an open-access article distributed unde the terms of the Creative Commons Attribution License, which permits unrestricted use, distribution, and reproduction in any medium, provided the original author and source are credited. 
if services were well organized, the majority of cases could not receive adequate orthodox psychiatric care they need [9].

The population of Nigeria is currently estimated to be about 150 million people, but there are inadequate numbers of available medical professionals to cater to the health needs of the nation [10]. The situation is even direr for mental health, with a psychiatrist to population ratio of $0.09 / 100,000$; while the ratio for the United Kingdom is about $9-25 / 100,000$. This roughly translates to one psychiatrist for every one million people in Nigeria [10]. The psychiatrist-patient ratio in Nigeria are therefore dismal, thereby widening mental health treatment Gap. Furthermore, the majority of available psychiatrists in the country are based in the urban and southern parts of Nigeria [11]. This situation is however, not exclusive to Nigeria but is also a common feature in most other African countries, such as Kenya, which has a ratio of one psychiatrist to 500,000 people [12].

Central norms for mental health institutions stipulate a psychiatrist for every 100 patients, a medical officer for every 100 patients and a ward attendant for at least five patients [13]. There is massive shortage of psychiatrists and the psychiatrist-patient ratio is widely off the mark. Medical officers double up as psychiatrists [13]. The ratio of doctor to patient ratio is not any different. It is simply appalling. It is about one doctor to 8,000 people. In the USA and UK, it is one doctor to 100 people [13]. Most Nigerian medical doctors currently work in the United States, Britain, South Africa, and other neighboring African countries, where medical personnel are treated better and facilities are better [14].

The burden of disease is high, even though existing resources are both scarce and deficient. These facts are plain enough, even if the means of redressing them have not been [7]. There is also dearth of research in all areas of mental health in this center, which has led to the continued exclusion of 28-year old Psychiatric hospital, Eket, in the mental health situation analysis in Nigeria, as it was not even mentioned as one of the mental health institutions in that report [15]. In Nigeria, prevalence of mental illness is $20 \%$ [15]. With a population of 150 million, this translates to the fact that about 30 million Nigerians are suffering from mental disorders [16].

Mental disorders of concern due to high prevalence and/or severity of condition include, but are not limited to, schizophrenia and bipolar disorder (referred to as severe mental disorders), depression, anxiety, somatoform disorders (referred to as common mental disorders), epilepsy, alcohol and substance abuse disorders and child and adolescent mental health problems [17]. In one study, it is noteworthy that of the DSM IV axis I diagnoses, $\mathrm{n}=307(70.0 \%)$ were accounted for by just three diagnoses; schizophrenia $(\mathrm{n}=207$ or $47.2 \%)$, Bipolar Disorder $(n=67$ or $15.3 \%)$ and schizoaffective disorder $(n=33$ or $7.5 \%)$ [18]. In Lagos, Nigeria, an average of 14.1 percent of the total population, suffers from one mental case or the other [19].

In another comparably, oil producing state, like the Kingdom of Saudi Arabia (KSA), the number of psychiatric hospitals in KSA has expanded nearly 10 -fold over the past 30 years to 21 specialty hospitals today. The number of psychiatrists has also been expanding in KSA. In 1977, there were only three psychiatrists to serve the entire population of KSA. By 1983, that number had increased about 10 -fold, and by 2006 there were 205 psychiatrists serving a population of 23 million $(0.9$ per 100,000) [20]. Conversely, in this Nigerian oil rich city but with comparatively meager economic resources and also social stigma attached to mental illness, there are profound shortfalls in the human resources and basic infrastructure, needed for adequate mental health care is dehumanizing and unacceptable. Women are not spared. A previous study brought to light, abysmal living conditions including overcrowding, lack of hygiene, inadequate general health facilities and in which the female were also found to be living under a constant physical violence $[21,22]$.

This study on health personnel shortage and infrastructure gap has not been done before in this area, to the best of available literature. This first attempt therefore has become imperative, with the purpose of bringing to global attention, the hitherto suppressed unacceptable level of degradation and human indignity going on at psychiatric hospital, in the oil rich city of Eket, which forced the Nursing and Midwifery council of Nigeria, to withdraw and rightly so, its accreditation for post basic psychiatric nursing training. It is also sad and sore reminder of failure of government all levels and the near failure of corporate social responsibility, being an oil rich city, leaving in its trail, a psychiatric hospital grossly deficient in minimally acceptable standards for medical care, but which has continued to render services to many in spite of the daunting challenges. It is also hoped that this study, will help to challenge the consciousness and conscience of policy makers, to stop excluding mental illness, from the overall concept of health and allow daring steps to be taken for the benefit of patients with mental illness.

\section{Materials and Methods}

\section{Location}

The study was done at the supposed 74-bed, Psychiatric Hospital, Eket, located in the city of Eket local government area of Akwa Ibom State, Nigeria. It was carved out of Immanuel Hospital, where it was a unit in internal Medicine but established as a full-fledged hospital 28 years ago in 1987. It currently has 4 female wards, 5 male wards and 18 beds (donated in September 2014 by the college of permanent secretaries in Akwa Ibom civil service), increasing it from an initial 6 beds, but still leaving a shortfall of 56 beds. It is the only psychiatric hospital in Akwa Ibom state and serves the state and some of the South Nigerian states. The city of Eket is estimated by the population census of 2011 to have a population of 204,890, according to the website of National Population Commission. Eket also acts as the operational and residential base of Exxon Mobil Producing Unlimited, which is a multi-national oil giant. The existence of the hospital is not being recognized in mental health reports, as it was not even mentioned among the eight psychiatric hospitals offering mental health care services in Nigeria. It was established in 1987, after the creation of Akwa Ibom state, from Cross River state in 1987.

\section{Population}

870 patients, who presented to the center over a 3-month period (May-July), were reviewed.

\section{Study design}

It is a cross sectional descriptive retrospective study.

\section{Data collection}

The Federal Ministry of Health, National Health management Information System, Health Facility Daily Attendance Register (Version 2013) was used to review the patients in terms of outpatient, inpatient, specialist medical care and outcome. The Hospital Inpatient Facilities Checklist (for Psychiatric Units), was used to access the level of facilities and compliance to standards at this center.

\section{Ethical consideration}

Approval for the study was gotten from the management of 
Citation: Nwaopara UA (2016) Doctor to Patient Ratio and Infrastructure Gap in a Psychiatric Hospital in Oil Rich Eket, Nigeria. J Psychiatry 19: 356 doi:10.4172/2378-5756.1000356

Page 3 of 8

Psychiatric Hospital, Eket and the Hospitals Management Board, Akwa Ibom State Nigeria, which is the supervising body in charge of the Hospital. Confidentiality was also assured.

\section{Statistical analysis}

Statistical Package for the Social Sciences (SPSS) Version 17.0 was used to analyze the data collected for the purpose of this study. Descriptive analysis was conducted for data analysis. Frequencies and proportions were used. Chi-square tests were conducted. Probability value of $p<0.05$ was considered as significant.

\section{Limitations}

Lack of electronic data base and diagnosis being made by nonpsychiatrists.

\section{Results}

Socio-demographic characteristics as depicted in Table 1 showed that out of the 870 patients reviewed within the study period of MayJuly, 2014, there was a slight preponderance of females with frequency of $51.4 \%$ compared $48.6 \%$ for males. The minimum and maximum ages of those considered were 5years and 92 years respectively, with the most predominant age range being 20-29 years with 317 (36.4\%) patients and $44.2 \%$ were below $30 y e a r s$. The mean age at presentation was 33.9 $(\mathrm{SD}=13.4)$. Majority of the patients $(61.0 \%)$ were single and $98.0 \%$ were Christians. Most patients (93.0\%) were from the Ibibio/Annang/ Efik tribe and 384 (44.4\%), and $36.2 \%$ had secondary and primary levels of education respectively. Table 2 shows the diagnostic profile of patients reviewed. Four hundred and one (46.1\%) were diagnosed with Schizophrenia, $11.6 \%$ for Depressive disorder, and $9.1 \%$ accounted for Mental and Behavioural Disorders secondary to psychoactive substance use. The least presentation was Hypochondriasis with $0.5 \%$. Table 3 shows the profile of professionals at the psychiatric hospital within the period covered. There was one psychiatrist within that period. There was however one other senior medical officer who acts as the medical superintendent but without any form of psychiatric training or updates other than the generally recommended continuing medical education, prescribed by the regulatory body, Medical and Dental Council of Nigeria discusses less of psychiatric issues. There were 43 nurses and one psychologist. The physician to patient ratio for the center within the period was 1:870. The doctor to patient ratio within same period was $1: 435$. However, this translates to a Physician to patient ratio of 0.5 per 100,000 in the Eket district. Table 4 is an exposition on the level of infrastructure at the psychiatric hospital Eket using the Hospital Inpatient Facilities checklist for psychiatric unit [22]. Findings were mind blowing. There were $6(8.1 \%)$ beds, out of a possible 72 , leaving a shortfall of $68(91.9 \%)$ beds. Other findings include, no laundry services, no toilet facilities, broken down plumbing systems, broken and open ceilings with high probability of escape, no separation of adult and pediatric patients, no renovation since inception of the center, prisonlike seclusion processes, chaining of all patients and a host of others as shown in Table 4. There was no separation of patients, as adults, children and adolescents, were mixed together. No specialized services were available for children and adolescents, drug and substance abuse and for geriatric patients.

\section{Discussion}

The results, in line with earlier researches $[3,19,20]$ indicate that the implementation of the right to health for people with mental disabilities is far from being achieved in Eket, south south Nigeria. To the knowledge of available literature, this is the first study and research

\begin{tabular}{|c|c|c|c|c|c|}
\hline Variables & $\begin{array}{c}\text { Frequency } \\
(n=870)\end{array}$ & $\begin{array}{c}\text { Percentage } \\
(\%)\end{array}$ & $\mathbf{X}^{2}$ & $\mathbf{p}$ & df \\
\hline \multicolumn{6}{|c|}{ Sex } \\
\hline Male & 423 & 48.6 & 1.08 & 0.29 & 1 \\
\hline Female & 447 & 51.4 & & & \\
\hline \multicolumn{6}{|c|}{ Marital status } \\
\hline Single & 531 & 61 & & & \\
\hline Married & 327 & 37.6 & 5.09 & 0.022 & \\
\hline Divorced & 12 & 1.4 & & & \\
\hline \multicolumn{6}{|c|}{ Age } \\
\hline$<10$ & 6 & 0.7 & & & \\
\hline $10-19$ & 62 & 7.1 & & & \\
\hline $20-29$ & 317 & 36.4 & & & \\
\hline $30-39$ & 240 & 27.4 & & & \\
\hline $40-49$ & 127 & 14.6 & 11.2 & 0 & 9 \\
\hline $50-59$ & 65 & 7.5 & & & \\
\hline $60-69$ & 34 & 3.9 & & & \\
\hline $70-79$ & 13 & 1.5 & & & \\
\hline $80-89$ & 3 & 0.3 & & & \\
\hline$>90$ & 3 & 0.3 & & & \\
\hline \multicolumn{6}{|c|}{ Religion } \\
\hline Christianity & 853 & 98 & 0.75 & 0.38 & 2 \\
\hline Islam & 11 & 1.3 & & & \\
\hline Traditional Religion & 6 & 0.7 & & & \\
\hline
\end{tabular}

Table 1: Sociodemographic characteristics of patients.

\begin{tabular}{|c|c|c|}
\hline Psychiatric Disorders & $\begin{array}{l}\text { Frequency } \\
(n=870)\end{array}$ & Percent (\%) \\
\hline Schizophrenia & 401 & 46.1 \\
\hline Depression & 101 & 11.6 \\
\hline Puerperal Psychosis & 37 & 4.3 \\
\hline MABD & 79 & 9.1 \\
\hline Seizure Disorders & 47 & 5.4 \\
\hline Dementia & 55 & 6.3 \\
\hline Mania & 44 & 5.1 \\
\hline Anxiety Disorder & 52 & 6 \\
\hline Post Stroke Depression & 4 & 0.5 \\
\hline Acute Psychosis & 14 & 1.6 \\
\hline Mental Retardation & 10 & 1.1 \\
\hline Dystonic Reaction & 10 & 1.1 \\
\hline Head Injury & 4 & 0.5 \\
\hline Schizoaffective Disorder & 8 & 0.9 \\
\hline Hypochondriasis & 4 & 0.5 \\
\hline Total & 870 & 100 \\
\hline
\end{tabular}

Table 2: Diagnostic profiles of patients. 
Citation: Nwaopara UA (2016) Doctor to Patient Ratio and Infrastructure Gap in a Psychiatric Hospital in Oil Rich Eket, Nigeria. J Psychiatry 19: 356 doi:10.4172/2378-5756.1000356

Page 4 of 8

\begin{tabular}{|c|c|c|c|}
\hline Variable & Frequency $(n=61)$ & $\begin{array}{l}\text { Median estimate per } 100,000 \\
\text { Population }\end{array}$ & Median estimate per 1,000 population \\
\hline Psychiatrist & 1 & 0.5 & 0.005 \\
\hline Other medical doctors & 1 & 0.5 & 0.005 \\
\hline Psychiatric nurses & 43 & 21.5 & 0.21 \\
\hline Social worker & 1 & 0.5 & 0.005 \\
\hline psychologist & 1 & 0.5 & 0.005 \\
\hline Occupational Therapy & 1 & 0.5 & 0.005 \\
\hline Pharmacist & 1 & 0.5 & \\
\hline Pharmacy technicians & 2 & 1 & 0.01 \\
\hline Ward assistants & 2 & 1 & 0.01 \\
\hline Other healthcare professionals & 9 & 0.04 & 4.5 \\
\hline Total & 61 & & \\
\hline
\end{tabular}

Table 3: Distribution of professionals in the centre.

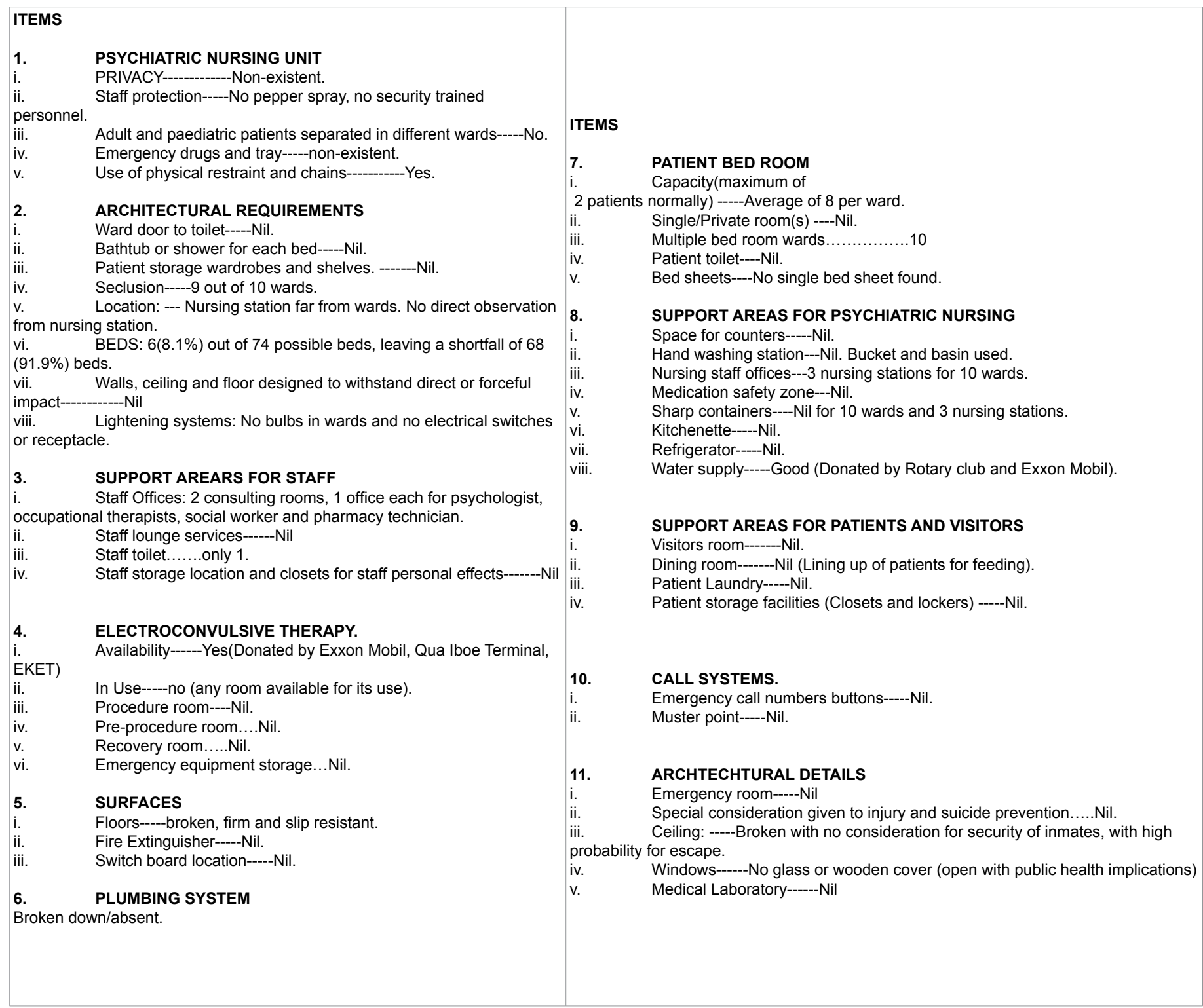

Table 4: Facility compliance using the hospital inpatient facilities checklist. 
in this 28year old center and region emphasizing this topic or other psychiatric issues because of dearth of research in the center. This is consistent with the finding that there have been fewer studies in low and middle income countries, despite the considerable burden posed by mental disorders,

Especially in Africa, in general and Nigeria in particular, with their potential impact on development [24].3.8\% of these beds are reserved for children and adolescents.

\section{Socio-demographic characteristics}

The finding of more female patients agrees with the higher frequency of female patients found in a Kenyan studies [12,25]. The study reaffirms the findings from other studies about the predominance of female patients. Females (50.4\%) are slightly more than males (49.6\%) [26], and with the higher values of $57.5 \%$ found in another related study [27] and $53.7 \%$ in a Kenyan study [12].

The higher number of females than males in the study was likely to be an illustration of attendance patterns [12] and the fact that females take their symptoms more seriously than males. The finding in this study that mean age was $33.9(\mathrm{SD}=13.9)$ years is related to participants' mean age on admission of $32.9(\mathrm{SD}=10.4)$ years and mean age $=34.2$ year found in other studies [12,18].

\section{Prevalence of psychiatric disorders}

The study has highlighted the relatively high prevalence of psychiatric disorders in the sample population used for the study. The most prevalent psychiatric disorder was schizophrenia (41.6\%), followed by Depression found in $101(11.6 \%)$. This agrees with the findings in other reports that admission diagnoses of patients to the communitybased psychiatric inpatient facilities were primarily schizophrenia and related disorders (43\%) [23] and schizophrenia being most prevalent (36.8\%) [27]. The less value in this study compared to the present study may be because of a smaller sample size. ( $n=106$ vs. $n=870$ in this study). This was reinforced in a finding in a London study that the proportion of admissions for schizophrenia and related psychoses was higher than for depression and anxiety in London [28].

\section{Physician (Psychiatrist) to patient and Psychiatrist to population ratios}

A variety of sources purport to show the number of physicians in various specialties required to meet the needs of a population of 100,000 people called physician to patient ratios [29]. Mental health services are labor-intensive, yet there is paucity of qualified mental health professionals [30], as evidenced in this present study. This problem is particularly acute for people with mental disabilities as shown by the related barrier lack of properly trained staff, including the huge shortage of psychiatrists who can properly identify and treat people with mental disabilities [31]. It also confirms that Eket Nigeria, like most low-income countries lack appropriately trained mental health personnel, and is constrained by the prevailing public-health priority agenda and its effect on funding [32]. The lack of psychiatrists is because the profession of psychiatry is not very popular and medical students do not opt for psychiatry as a specialty [32]. In this hospital, medical officers were offering psychiatric services, which is consistent with the fact that medical officers also double up as psychiatrists [13].

Consequently, based on the psychiatrist to population ratio of $0.48: 100,000$, and doctor to patient ratios of 1:870 and 2:435 patients respectively, found in this study, this center can rightly be referred to as a Health professional shortage area (HPSA) because Mental Health
HPSAs are based on a psychiatrist to population ratio of 1:30,000 and a Medically Underserved Areas (MUAs) may a group of county or civil divisions or a group of urban census tracts in which residents have a shortage of personal health services [33]. This is true because of the number of inadequate number of nurses, psychologist, social worker, occupational therapist, pharmacist and other support staff available in this center. It is noteworthy that this staff-patient ratios, significantly predicted unit effectiveness [34].

The statistics found in this center contradicts other statistics both in Africa and internationally. In Northern Ireland, the total numbers of doctors seemed adequate [35]. The ratio for this center is far below that of the United Kingdom which is about 9-25/100,000 [10]. In contrast to the one doctor to 870 found in this study, in the USA and UK, it is one doctor to 100 people [13]. Other reports show that this center, falls below that of other major cities. In Arkansas, doctors per 100,000 people: 169, New Jersey, while in New York, doctors per 100,000 people: 277.4. The situation in Austria is 11.8 psychiatrists per 100000 inhabitants [18], while in Singapore, there are 108 psychiatrists on the specialist register, giving a psychiatrist: population ratio of about 2.6:100 000 [36]. The reason is that with its 13 accredited medical schools the state can more easily attracts doctors since these schools provide residency opportunities and New York has also attracted many overseas-trained physicians [37]. Conversely, there is no provision for residency training in Eket, or facilities to attract specialist physicians. The situation in Eket is also not different from that of Nigeria, where there is abysmal shortage of specialist doctors because little or no importance is placed on the training of doctors and other health professionals [38]. Another reason is that, most Nigerian specialist medical doctors currently work in the United States, Britain, South Africa, and other neighboring African countries, where medical personnel are treated better and facilities are better [14]. Even countries that have shortage of specialists, theirs is still better than that of Nigeria. According to the United States government, Morocco has inadequate numbers of physicians ( 0.5 per 1,000 people) and in Ethopia, the physician to population ratio was 1:48,000 [39]. It in Kenya that a lesser psychiatrist to patient ratio was found with a physician to population ratio there is only 1 psychiatrist per 500,000 populations [25]. This may be because Nigeria is a more endowed country than Kenya, with more abundant human and material resources. It also reinforces the fact that in many countries there are acute shortages of professionals who have traditionally been at the forefront of providing assistance for people with mental health needs, including social workers [30]. Study findings also agree that in low and middle income countries, there are low levels of personnel and resources for mental health services [2]. The implication of the shortage of health professional found in this study means that mental health professionals at the secondary level of health care are overwhelmed with the volume of cases [24].

\section{Infrastructure gap}

Findings from this study show that, notwithstanding this visibility of burden, the field of global mental health can also be characterized by its inordinate resource gaps resulting in tragically high and persistent unmet needs [7]. The inadequacy has been reported not only in the form of quantity but also in the quality of mental health services [4]. Nothing can be farther from the truth, that many of the existing institutions are too old to be amenable for repair, meaning that new hospitals may have to be built to replace the old ones [4], than the fact that this index hospital is 28 years old, without any kind of renovation of its obsolete structures. It also agrees with what was found that 14 facilities had not undergone any structural transformations since 1980 
[17].

Sadly, even though Nigeria formulated a Mental Health Policy document in1991, addressing mental health issues and its components which include advocacy, promotion, prevention, treatment and rehabilitation, it has however not been revised since then. Furthermore, no formal assessment has been conducted to check its level of implementation [15]. This is what has made it possible for the decay at this study center to go on unnoticed and unreported for over a decade and half. Noteworthy is the fact that rehabilitation facilities and residential programs for people with chronic mental illness do not exist in this facility and region [40]. No institution depicts this failure of policy direction in mental health, than the psychiatric hospital Eket.

Several reports have expressed disquiet about the environment in acute psychiatric facilities like the one in this center studied [15,24]. This decay has been going on for over a decade without adequate representation in learned journals, media houses and policy statements. In the study center, patients do not have privacy and there is concern that patients often do not have privacy, nor are they guaranteed the therapeutic and recreational facilities that are a necessary part of good care [41,42]. Women are not spared, as the situation depicted in this report that, there is clear evidence that women are particularly disadvantaged with regard to both privacy and safety [42]. There is also frequent violation of the basic human rights of patients, such as the right to confidentiality, to privacy and to communication, with women undergoing constant violence $[17,22]$.

Another related problem is the virtual nonexistence of specialized facilities for mental health care, one of the more critical, being the lack of facilities for children under age of 15 years [31]. This situation is particularly worrying, even in this center, since children with mental disabilities belong to two particularly vulnerable groups at the same time, and whose situation must be considered from an intersectional perspective. From a human rights perspective, the lack of treatment facilities for children and the lack of properly trained staff to deal with children's mental disabilities had become violations of the right to health [31]. There can only contribute to widening the treatment gap.

Unhygienic and inhuman living conditions are commonplace in the study center, as are in harmful, degrading practices. This is related to the conclusion that in many facilities, poor hygiene, harmful and degrading treatment practices exists, where patients are locked up in these institutions against their will for long periods, even years [17]. Informed consent to treatment is systematically ignored in some cases, while in others people are subject to neglect and receive no treatment or care [17].

The finding that there were no toilets and most patients slept on the floor reinforces the fact that in many mental hospitals in the tropics, placed patients in cells without water facilities, toilets, or beds, so people had to urinate and defecate in the wards $[4,17]$. In this center, there are no functional toilets and patients defecate on the ground with foul smelling mattresses, as was the case related studies $[6,43]$. Overcrowding is another feature. The recommendation of 2 patients per room is violated because many patients are kept in one room. Sixteen hospitals used single-person cells to house several patients [17]. The public health implications of this are enormous, and the risk and consequences of an outbreak of epidemic can only be better imagined. The situation in the study center is even made worse by the leaking roofs, eroded doors, no window blinds or panes, and broken doors [6]. This should lead to increasing concerns about both the adequacy of current levels of provision and the quality of the care provided [28].
It shows gross neglect $[3,6]$ and the lip service being paid to mental Health care structures and service by concerned authorities [7].

The hospital used for this study retained a prison-like structure and ambience with patients locked in iron crested doors and patients put in big chains like it was in a related study [5]. In contrast however, it is possible to walk into Donka hospital's psychiatric unit without realizing it. That alone is enough to differentiate this ward in the capital city of the Republic of Guinea from its counter parts in the United States, where such units typically feature heavy doors that lock behind you after you've been buzzed in. Donka feels more like a hospital and a lot less like a prison [43]. Considering the fact that Donka, Guinea is not blessed with mineral resources and wealth like Eket, shows the premium placed on a conducive environment for these vulnerable groups. It is noteworthy that in Donka, there are no psychiatric isolation rooms and they haven't used any form of mechanical restraint since 1996, making it one of a small percentage of psychiatric hospitals worldwide to have eliminated them entirely [43]. This is a complete opposite of what is found in this psychiatric hospital in an oil rich city and is worthy of emulation.

There is acute shortage of beds in this center with a bed shortfall of $91.8 \%$ and a bed to population ratio of $3: 100,000$. This falls into the category of critical bed shortage $(<12$ beds per 100,000$)$, with many patients lying on the floor $[4,44]$. The pressure on beds appears to reflect a wider mismatch of provision and need [28]. This is in consonance with the fact that shortage of beds in acute psychiatric units is related to both social deprivation and the overall availability of acute beds $[41,42]$. It is reported that South Africa, Egypt, Ethiopia and Kenya have higher proportions of psychiatric beds, with the neuropsychiatric hospital, Aro Hospital having over 500 beds [24,39]. Ethiopia has a hospital bed to patient ratio of 1.0 per 1,000 people [39]. This may be because of better funding, management and multi sectoral and international collaboration. Conversely the number of beds in advanced countries like England is falling not because of shortage or non-availability but because of deinstitutionalization $[28,30]$.

The implication of all these therefore, is that within each local health community, the requirement for acute mental health beds needs to be assessed in the context of the whole mental health system [28].

\section{Conclusion}

In view of the virtual neglect suffered by this hospital over the years, it has become crucial, in fact more than critical, to re-equip the entire facility to make it justify its existence, and to ensure it continues to render the needed crucial services to our fellow citizens who access the care provided by this hospital. It is this realization that will make the state government to adopt a policy that aims to respect the rights of residents with mental disorder. This goal will guarantee social justice and equity for victims of mental illness as well as ensuring that the rights of people suffering from mental disorders are respected. This new approach will include sufficient and detailed strategies aimed at reducing the impact of mental health in the state. It is the hope of the author, that the report will be an impetus for making the necessary improvements in the mental health system in the state in particular and Nigeria in general.

The issues that are highlighted in this article are necessary, but probably not sufficient, to reshape the state governments response to mental health problems. In addition, what is needed is understanding of those political, economic, and socio-cultural barriers that have for so long impeded mental health care and that have placed it at serious 
disadvantage within globally acceptable health care standards. Among these barrier which, for so long, have allowed an outrageous reality to persist with so little outcry, are a politics of indifference and the ravages of stigma, which becomes a social death to sufferers of the most serious mental illnesses.

Issues of mental health in Eket as in most parts of Nigeria, are indeed multifarious and need very deliberate, specific and concerted actions. Poverty and consequent stresses associated with poor infrastructure in Nigeria, human rights protections, the pervasive role of religion in a lot of mental problems and availability and accessibility of mental health care facilities are fundamental issues that have to be addressed in order to effectively grapple with the mental health challenges of citizens.

Overcoming these many challenges will require the kind of political activism, for which the HIV/AIDS movement has been such a sterling example. It will also require consciousness rising-to which this article hopes to contribute by its very publication.

\section{Recommendation}

It is recommended that there be an urgent review of the therapeutic suitability of district general hospital mental health units. A state mental health policy in line with the National Mental Health policy is advocated. The basic components of a state's mental health policy will include promotion aimed at conducting awareness programmes and educating the people on the effects of substance and alcohol abuse, primary care and access to services, treatment guidelines at health care level, services for people with severe mental illness, reduction of work place stress and the risk of suicides and building human resources and capacity for mental health. The first step in this new policy is investment in mental health infrastructure across the state. This report suggests that there should be a comprehensive review of how mental health service is provided and that there should be a plan for addressing any systemic issues. The development of community-based services therefore requires the education and training of appropriate personnel, including psychiatrists, social workers, psychiatric nurses and psychologists [30].

Finally, a reversal of this ugly trend of provider patient ratios and mental health institutional infrastructure mismatch will help to improve efficiency in service delivery, as well as optimize patient care.

\section{Conflict of interest}

The author confirms that there is no conflict of interest.

\section{Funding}

None declared.

\section{References}

1. World Health Organization (2011) Mental Health Atlas 2011

2. Uwakwe R, Otakpor A (2014) Public Mental Health-Using the Mental Health Gap action program to put all hands to the pumps. Front Public Health 2: 33.

3. Pinaman A (2013) Speech delivered by Dr. Pinaman Apau on behalf of the chief psychiatrist/medical director, ACCRA psychiatric hospital. ACCRA psychiatric hospital.

4. Thirnavukarasu M (2011) Closing the treatment gap. Indian J Psychiatry 53: 199-201.

5. National Human Rights Commission (1999) Quality Assurance in Mental Health.

6. Thirunavukarasu M, Thirunavukarasu $P(2010)$ Training and National deficits of Psychiatrists in India-A critical analysis. Indian J Psychiatry 52: 83-88.

7. Becker A, Kleinmain A (2012) An Agenda for closing resource gaps in Global Mental Health; Innovation, Capacity building and Partnerships. Harv Rev
Psychiatry 20: 3-5.

8. World Health Organization (2008) The global burden of disease: 2004 update. Health statistics and information systems.

9. Ewhrudjakpor C (2010) Psychiatric Institutions and the Emerging Institutional scene in Nigeria. Afr Res rev 4: 132-147.

10. Wakil MA, Abdul IW, Abdulmalik JO, Salami FK, Ahidjo A (2010) Attitude and future career interest in Psychiatry oof medical students from University of Maiduguri, North East Nigeria. BOMJ 7: 1-17.

11. Gureje O (2003) Revisiting the national mental health policy for Nigeria. Arch Ibadan Med 4: 2-4.

12. Ndetei DM, Ongecha FA, Mutiso V, Kuria M, Khasakhala LI, et al. (2007) The challenges of human resources in mental health in Kenya. S. Afr Psychiatry Rev 10: 33-36.

13. Barnagarwala T (2014) Wanted: Sensitive staff at state mental hospitals. The Indian Express.

14. World Health Organization (2006) Doctor to patient ratio in Africa. Afripedia.

15. Mental Health Leadership and Advocacy Programme (2012) Mental Health Situation analysis in Nigeria. University of Ibadan, Nigeria.

16. Attah N (2013) Addressing Mental Health Challenges and inadequate services in Nigeria. Cheld.

17. World Health Organization (2009) Addressing non-communicable diseases and mental health. Major challenges to sustainable development in the $21^{\text {st }}$ century. ECOSOC Meeting.

18. Niehaus DJ, Koen L, Galal U, Dhansay K, Oosthuizen PP, et al. (2008) Crises discharges and readmission risk in acute psychiatric male inpatients. BMC psychiatry 8: 44 .

19. All Africa (2014) World Mental Health Day -Nigeria: Mental illness as a Time bomb. Daily Independent (Lagos).

20. Deutsche Welle (2014) Indian women in mental hospitals "treated worse than animals," says HRW. DW Made for minds.

21. Sharan P, Gallo C, Gureje O, Lamberte E, Mari JJ, et al. (2009) Mental Health resources in low and middle income countries of Africa, Asia, Latin America and the Caribbeans. Br J Psychiatry 195: 354-363.

22. Health and Human Services (2015) Hospital Inpatient facilities Checklist. Executive Office of Health and Human Services.

23. World Health Organization (2006) WHO-AIMS Report on Mental Health systems in Nigeria. Ministry of Health, Nigeria.

24. Thompson A, Shaw M, Harrison G, Ho D, Gunnell D, et al. (2004) Patterns of hospital admissions for adult psychiatric illness in England. Analysis of Hospital Episode Statistics data. Br J Psychiatry 185: 334-341.

25. Jenkins R, Njenga F, Okonji M, Kigamwa P, Baraza M, et al. (2012) Prevalence of common disorders in a rural district of Kenya and Socio-demographic risk factors. Int J Environ Res Public Health 9: 1810-1819.

26. Khattri JB, Godar ST, Thapa P, Ramesh K, Chakraborthy PK, et al. (2012) Socio-demographic characteristics and diagnostic profile of patients attending psychiatric OPD in a private Hospital in Western Region of Nepal. Nepal J Med Sci 1: 15-18.

27. Potkonjak J, Karlovic D (2008) Sociodemographic and medical characteristics of involuntary psychiatric inpatients--retrospective study of five-year experience with Croatian Act on Mental Health. Acta Clin Croat 47: 141-147.

28. Addisu F, Wondafrash M, Chemali Z, Dejene T, Tesfaye M (2015) Length of stay of Hospital admissions in a general Hospital in Ethopia: a Retrospective study. Int J Ment Health Syst 9: 13.

29. Koenig HG, Al Zaben F, Sehlo MG, Khalifa DA, Al Ahwal MS, et al. (2014) Mental Health Care In Saudi Arabia: Past, Present, Future. Open J Psychiatry 4: 113-130.

30. Medeiros H, McDavid D, Knapp M, MHEEN Group (2008) MHEEN II Policy Briefing: Shifting Care from Hospital to the Community in Europe; Economic challenges and opportunities. Personal social services Research Unit. pp: 1-24.

31. Merritt Hawkins (2014) A review of physician to population Ratios. AMN Healthcare Company. 
Citation: Nwaopara UA (2016) Doctor to Patient Ratio and Infrastructure Gap in a Psychiatric Hospital in Oil Rich Eket, Nigeria. J Psychiatry 19: 356 doi:10.4172/2378-5756.1000356

Page 8 of 8

32. Schierenbeck I, Johansson P, Andersson C, van Rooyen D (2013) Barriers to accessing and receiving mental health care in Eastern Cape, South Africa. Health Hum Rights 15: 110-123.

33. Jack-Ide IO, Uys LR, Middleton LE (2012) A comparative study of Mental Health Services in 2 African Countries, South Africa and Nigeria. Int J Nurs Midwifery 4: 50-57

34. Health Resources and Service Administration (2015) Shortage Designation: Health Professional Shortage Areas \& Medically underserved Areas/ populations. U.S. Department of Health and Human Services.

35. Coleman J, Paul G (2001) Relationship between staffing ratios and effectiveness of inpatient psychiatric units. Psychiatric Serv $52: 1374-1379$

36. Weigley S, Hess AEM, Sauter MB (2012) Doctor Shortage could take a turn for the worse. USA today Money.

37. Chiejina A (2013) Dearth of Specialist Doctors threatens Nigeria's Health Sector. Business Day.
38. Chong SA (2007) Mental Health in Singapore: A Quiet Revolution?. Annals Academy of Medicine 36.

39. Chacko S, Prabhavalkar D (2014) Doctor Patient Ratios and Acute Medical admission: A simple solution to a simple problem. Ulster Med J 83: 54-55.

40. Health Systems by Country. Accessed on September 3, 2015

41. Goldberg D (1998) Acute Problems: Survey of the quality of care in acute psychiatric wards. Sainsbury Centre for Mental Health, BJPsych Bulletin.

42. Shepherd G, Beadsmoore A, Moore C, Hardy P, Muijen M (1997) The relationship between bed use, social deprivation, and $\mathrm{s}$ and overall bed availability inn acute adult psychiatric units and alternative residential options: A cross sectional survey. One day census and staff interviews. BMJ 314: 262266.

43. Torrey EF, Entsminger K, Geller J, Stanley J, Jaffe DJ (2015) The Shortage of Public Health Hospital beds for Mentally ill Persons. Montana 303: 6-9.

44. Phalen P (2013) Guinea Hospital shows West How to treat Mental IIIness without Chains. Humanosphere. 